\title{
A Note on Resources
}

We hope that this book will be used not only for its theoretical and empirical insights but also as a resource, for inspiration and for guidance, by those who are carrying out activist research or who aspire to do so. Toward this end, we have prepared an online appendix, meant to be a guide to organizations, networks, and the like that work in this field. Interested readers may find it alongside the online version of this book, at http://repositories.cdlib.org/gaia/gaia_books/6/.

The appendix is intended to provide activist scholars with the names and contact information of activist research centers in North America, Latin America, Asia, Africa, Oceania, and Europe, as well as to give a general sense of the types of areas in which research has been combined with concrete community action. The guide is not intended to be exhaustive but rather representative of the different types of activist research initiatives currently under way. 
